\title{
28000 Cases of age related macular degeneration causing visual loss in people aged 75 years and above in the United Kingdom may be attributable to smoking
}

\author{
J R Evans, A E Fletcher, R P L Wormald
}

Br J Ophthalmol 2005;89:550-553. doi: 10.1136/bjo.2004.049726

Background: Age related macular degeneration (AMD) causing visual impairment is common in older people. Previous studies have identified smoking as a risk factor for AMD. However, there is limited information for the older population in Britain.

Methods: Population based cross sectional analytical study based in 49 practices selected to be representative of the population of Britain. Cases were people aged 75 years and above who were visually impaired (binocular acuity $<6 / 18$ ) as a result of $A M D$. Controls were people with normal vision (6/6 or better). Smoking history was ascertained using an interviewer administered questionnaire.

Results: After controlling for potentially confounding factors, current smokers were twice as likely to have AMD compared to non-smokers (odds ratio $2.15,95 \% \mathrm{Cl} 1.42$ to 3.26 ). Exsmokers were at intermediate risk (odds ratio $1.13,0.86$ to 1.47). People who stopped smoking more than 20 years previously were not at increased risk of $A M D$ causing visual loss. Approximately 28000 cases of AMD in older people in the United Kingdom may be attributable to smoking.

Conclusion: This is the largest study of the association of smoking and $A M D$ in the British population. Smoking is associated with a twofold increased risk of developing AMD. An increased risk of $A M D$, which is the most commonly occurring cause of blindness in the United Kingdom, is yet another reason for people to stop smoking and governments to develop public health campaigns against this hazard.

$\mathrm{V}$ isual impairment is common in older people in Britain. Its prevalence increases progressively with increasing age. Age related macular degeneration (AMD) is the most important cause of visual impairment. ${ }^{2}$ Currently there are estimated to be approximately 200000 people aged 75 years and above visually impaired due to AMD in the United Kingdom. ${ }^{3}$ There is no treatment that can restore visual loss in people with AMD. ${ }^{5}$ In order to develop preventive strategies we need to understand why some people develop AMD and others do not.

Previous studies have identified smoking as a risk factor for AMD. ${ }^{6}$ However, these studies have not included many people aged 75 years and above, which is the population group that bears the burden of AMD in the United Kingdom. In addition, to our knowledge there have been no published studies in the British population that have examined this risk factor specifically.

The population based MRC trial of the assessment and management of older people in the community ${ }^{7}$ offered the opportunity to identify a large number of representative cases of severe AMD and to compare them to a population based control group.

\section{METHODS}

The MRC trial of the assessment and management of older people in the community is a large cluster randomised trial taking place in 106 general practices from the MRC General Practice Research Framework. ${ }^{7}$ The practices in the study were selected to be representative of the mortality (SMR) and Jarman scores of general practices in Britain (England, Wales, and Scotland). The aim of the trial was to compare the cost effectiveness of different methods of assessment and management of older people in the context of the 1990 contract of service which required general practitioners to offer an annual health check to patients aged 75 years and over. The study compared two different types of multidimensional assessment (targeted versus universal) and two different management models (primary care team versus multidisciplinary geriatric evaluation team). Randomisation was at the practice level and stratified by SMR and Jarman score. All patients aged 75 years or over on the general practitioner list were invited to participate in the trial, unless they were in long stay hospital or nursing homes, or were terminally ill.

People in the 53 practices allocated to the "universal" arm of the trial were given a visual acuity test as part of a detailed health assessment by the practice nurse. Visual acuity was measured at 3 metres with a Glasgow acuity chart which measures the minimal angle of resolution on a logarithmic scale $\left(\log\right.$ MAR). ${ }^{8}$ Binocular vision was measured first, followed by vision in the right and left eyes. All vision measurements were conducted with usual spectacle correction. People with visual acuity of 0.5 or more in either eye (equivalent to less than 6/18 Snellen acuity) were retested with a pinhole occluder. If vision did not improve to less than 0.5 , and the cause of visual loss had not previously been investigated, the person was referred to an ophthalmologist. If vision improved to less than 0.5 , the patient was advised to see an optometrist. Visual impairment was defined as presenting binocular acuity of less than 6/18 (logMAR score 0.5 or more). In 49 practices, the cause of visual impairment was assessed by medical record review. ${ }^{9}$ The trial and additional data collection on causes of visual loss were approved by the relevant local research ethics committees.

People with AMD causing visual impairment were considered as "cases" and compared to a "control" group. There were two different options for selection of the control group. Firstly, to compare people visually impaired due to AMD with the rest of the MRC trial study population. This control group would include people visually impaired as a result of other

Abbreviations: $A M D$, age related macular degeneration; ARM, age related maculopathy 
Table 1 Cases and controls by age and sex

\begin{tabular}{|c|c|c|c|c|c|c|}
\hline \multirow[b]{2}{*}{ Age group } & \multicolumn{3}{|c|}{ Controls } & \multicolumn{3}{|l|}{ Cases } \\
\hline & Male & Female & Total & Male & Female & Total \\
\hline 75-79 & 1344 & 1504 & 2848 & 26 & 48 & 74 \\
\hline $80-84$ & 511 & 633 & 1144 & 47 & 112 & 159 \\
\hline $85-89$ & 123 & 187 & 310 & 45 & 131 & 176 \\
\hline $90+$ & 21 & 41 & 62 & 20 & 87 & 107 \\
\hline Total & 1999 & 2365 & 4364 & 138 & 378 & 516 \\
\hline
\end{tabular}

causes and people not visually impaired. The second option considered was to compare people visually impaired due to AMD with people with good vision (that is, visual acuity of $6 / 6$ or better).

The signs and symptoms of AMD form a continuous spectrum. Dichotomising the disease, as in many other conditions, is essentially arbitrary. In this study, relatively severe AMD cases were selected because a cut-off point of visual acuity worse than $6 / 18$ was used to identify them. It is likely that a small proportion of people with vision worse than 6/6 and better than, or equal to, 6/18 will have AMD and a larger proportion will have early age related maculopathy (ARM) - that is, drusen and pigmentary changes putting them at increased risk of developing AMD.$^{10}$ For this reason, in order to minimise the number of controls who have AMD or ARM, a control group of people with good vision-that is, binocular visual acuity of $6 / 6$ or better, was selected.

Smoking history was ascertained using an interviewer administered questionnaire. The questions used came from the Whitehall study. ${ }^{11}$ Participants were asked whether they smoked currently. For people who responded no, they were asked whether they had ever smoked cigarettes. Age smoking started and stopped was also elicited and the number of cigarettes (ounces ( $\mathrm{g}$ ) tobacco) smoked a day. One ounce (28 g) of tobacco was assumed to correspond to 30 cigarettes.

The following variables were created:

- Smoking status $1=$ never smoked $2=$ ex-smoker $3=$ current smoker.

- Pack years were calculated from the number of years participants had smoked, multiplied by the usual daily cigarette equivalent intake, and divided by 20 . This gives a measure of the lifetime exposure dose received.

- The number of years since stopping smoking was calculated from the current age minus the age stopped smoking. People who were still smoking had a value of 0; people who had never smoked were excluded from this variable.

The following confounding factors were considered because they have been reported in other studies as putative risk factors for AMD: socioeconomic status, alcohol consumption, cardiovascular disease and its risk factors. Data were not available on antioxidant micronutrient intake, exposure to light (visible or ultraviolet), and family history of AMD.

All regression analyses took account of the extra variation introduced by the cluster design of the study using the "svy" commands in Stata version 8.0 (Stata Corporation, TX, USA). "Svy" commands calculate robust standard errors using the "linearisation" variance estimator (based on a first order Taylor series linear approximation).

\section{RESULTS}

Controls were younger and less likely to be women (table 1); $9.0 \%$ of the study population were current smokers. Smoking decreased with increasing age $(\mathrm{p}<0.001)$ and was higher in men $(11.2 \%)$ than women $(7.3 \%)(\mathrm{p}<0.001)$. Table 2 shows the association between current smoking and risk of AMD causing visual impairment by age.

After controlling for potentially confounding factors, current smokers were twice as likely to be a case compared to non-smokers (odds ratio 2.15, 95\% CI 1.42 to 3.26 ) (table 3). There was little or no association for ex-smokers (odds ratio $1.13,0.86$ to 1.47 ). There was an increased chance of AMD causing visual loss with increasing pack years of smoking, however, this increase was not seen consistently after controlling for confounding factors.

There was an increased association of AMD with decreasing years since stopping smoking (test for linear trend $\mathrm{p}<0.001$ ). People who stopped smoking more than 20 years previously did not have increased odds of AMD causing visual loss. There was a moderately increased odds ratio for AMD for people who stopped smoking 10-20 years ago. The adjusted odds ratio comparing people who had stopped smoking $10-<20$ years ago with those who had stopped smoking 20 years ago or more or who had never smoked was 1.46 (95\% CI 1.03 to 2.07). Comparing people who were current smokers, or who had stopped smoking less than 10 years ago, with people who had stopped smoking 20 years ago or more, or who had never smoked, gave an adjusted odds ratio of 2.29 (95\% CI 1.69 to 3.10 ).

Based on current estimates of the number of people with AMD causing visual loss in the United Kingdom, ${ }^{3}$ this equates to approximately 28000 people (95\% CI 17000 to

Table 2 AMD causing visual impairment associated with smoking by age

\begin{tabular}{llll}
\hline Age group & Odds ratio* & $95 \% \mathrm{Cl}$ & $\mathbf{p}$ Value \\
\hline $75-79$ & 2.89 & 1.40 to 5.94 & 0.003 \\
$80-84$ & 1.85 & 1.09 to 3.15 & 0.022 \\
$85-89$ & 1.38 & 0.69 to 2.78 & 0.361 \\
$90+$ & 0.93 & 0.25 to 3.44 & 0.915 \\
\hline & Mantel-Haenszel estimate of the odds ratio controlling for the effects of age $=1.78$ (95\% confidence intervals 1.26 \\
to 2.52) p=0.001. & \\
*Odds of being a case if current smoker divided by odds of being a case if a non-smoker.
\end{tabular}


Table 3 Association between smoking and AMD causing visual impairment

\begin{tabular}{|c|c|c|c|c|c|c|c|c|}
\hline \multirow[b]{2}{*}{ Risk factor } & \multirow[b]{2}{*}{ Controls } & \multirow[b]{2}{*}{ Cases } & \multicolumn{3}{|c|}{ Odds ratio adjusted for age and sex } & \multicolumn{3}{|c|}{ Odds ratio adjusted for confounders } \\
\hline & & & OR & $95 \% \mathrm{Cl}$ & Wald test & OR & $95 \% \mathrm{Cl}$ & Wald test \\
\hline Never smoked & 1698 & 233 & 1 & & & 1 & & \\
\hline Ex-smoker & 2281 & 220 & 1.13 & 0.88 to 1.44 & 0.382 & 1.13 & 0.86 to 1.47 & 0.376 \\
\hline Current smoker & 378 & 60 & 2.33 & 1.61 to 3.37 & $<0.001$ & 2.15 & 1.42 to 3.26 & 0.001 \\
\hline Never smoked & 1698 & 233 & 1 & & & 1 & & \\
\hline$<20$ pack years & 1286 & 143 & 1.18 & 0.90 to 1.55 & 0.214 & 1.17 & 0.86 to 1.58 & 0.303 \\
\hline $20-<40$ pack years & 619 & 57 & 1.31 & 0.90 to 1.92 & 0.160 & 1.37 & 0.93 to 2.01 & 0.108 \\
\hline $40+$ pack years & 627 & 59 & 1.41 & 0.96 to 2.05 & 0.075 & 1.24 & 0.80 to 1.93 & 0.336 \\
\hline Never smoked & 1602 & 229 & 1 & & & 1 & & \\
\hline Stopped $20+$ years & 1588 & 140 & 0.89 & 0.69 to 1.17 & 0.399 & 0.86 & 0.65 to 1.14 & 0.295 \\
\hline Stopped $15-<20$ years & 273 & 25 & 1.33 & 0.85 to 12.08 & 0.213 & 1.33 & 0.82 to 2.14 & 0.241 \\
\hline Stopped $10-<15$ years & 223 & 20 & 1.42 & 0.87 to 2.34 & 0.160 & 1.41 & 0.80 to 2.48 & 0.233 \\
\hline Stopped $5-<10$ years & 135 & 16 & 2.39 & 1.29 to 5.00 & 0.015 & 2.46 & 1.28 to 4.72 & 0.008 \\
\hline Stopped $<5$ years & 92 & 16 & 2.54 & 1.55 to 3.20 & 0.008 & 2.24 & 1.01 to 4.96 & 0.047 \\
\hline Current smoker & 388 & 61 & 2.37 & 1.63 to 3.45 & $<0.001$ & 2.02 & 1.36 to 2.99 & 0.001 \\
\hline \multicolumn{9}{|c|}{$\begin{array}{l}\text { Data from } 4364 \text { controls and } 516 \text { cases in the } 49 \text { practices taking part in the vision add-on study in the MRC Trial of the Assessment and Management of Old } \\
\text { People in the Community. Confidence intervals adjusted for clustered design of the study. Confounders: age (75-79, 80-84, 85-89, and } 90+) \text {, sex, housing } \\
\text { (owner, non-owner, sheltered), body mass index (quintiles), alcohol consumption (never, ex, current below median, current above median), cardiovascular diseas } \\
\text { (reported heart attack or stroke or angina as assessed by Rose questionnaire), hypertension (reported high blood pressure or current systolic }>160 \text { mm Hg or } \\
\text { current diastolic }>90 \mathrm{~mm} \mathrm{Hg} \text { ). }\end{array}$} \\
\hline
\end{tabular}

$36000)$ (where the attributable risk $\%=((\mathrm{OR}-1) / \mathrm{OR}) \times$ proportion exposed among cases).

\section{DISCUSSION}

This is the largest study of the association of smoking and AMD in the British population and one of the largest reported to date internationally. The results fit in remarkably well with results seen in studies from other countries with different designs, ages studied, and methods of ascertainment of AMD. ${ }^{6}{ }^{12-20}$ Smoking is associated with a twofold increased risk of developing AMD. The benefit for stopping smoking is seen after 10 years with reductions in risk although risks do not return to that of never smokers till 20 years after stopping smoking. The result for smoking is also consistent with the known pro-oxidant damage due to tobacco-for example, through DNA damage. ${ }^{21} 22$

We estimate that approximately 28000 cases of AMD in older people in the United Kingdom may be attributable to smoking. This is lower than estimates published in a recent editorial (54000). ${ }^{23}$ Our study provided a lower estimate of risk (twofold instead of threefold) and we used more conservative estimates of the population burden of AMD. In addition, our age range was more restricted (75 years and older rather than 70 years plus).

In contrast with other studies, we did not find a consistent dose-response relation with pack years of smoking. This may be the result of the difficulty of remembering and assessing smoking exposure over a lifetime in this elderly population.

The current study was limited by not having information on antioxidant intake. One alternative explanation is that smokers eat less fruit and vegetables and thereby increase their risk of AMD. However, other studies have been able to adjust for plasma levels of antioxidant micronutrients and have reported similar size effects for smoking. ${ }^{24}$

An increased risk of AMD, which is the most commonly occurring cause of blindness in the United Kingdom, is yet another reason for people to stop smoking and governments to develop public health campaigns against this hazard.

\section{CONTRIBUTORS}

All authors were involved in the design, interpretation and write-up of the study; JE did the data collection and analysis and acts as guarantor of the paper; $\mathrm{AF}$ is the principal investigator of the MRC Trial of Assessment and Management of Older People in the Community.

\section{Authors' affiliations}

J R Evans, International Centre for Eye Health, London School of Hygiene and Tropical Medicine, Keppel Street, London WC1E 7HT, UK

A E Fletcher, Non Communicable Disease Epidemiology Unit, London School of Hygiene and Tropical Medicine, Keppel Street, London WC1E 7HT, UK

R P L Wormald, Moorfields Eye Hospital and International Centre for Eye Health, London School of Hygiene and Tropical Medicine, Keppel Street, London WC1E 7HT, UK

Source of funding: The MRC Trial of the Assessment and Management of Older People in the Community was funded by the United Kingdom Medical Research Council, the Department of Health and the Scottish Office. Collection of data on causes of visual impairment was funded by the Gift of Thomas Pocklington. Researchers were independent of the funding body.

Competing interests: none declared

Correspondence to: Jennifer R Evans, International Centre for Eye Health, London School of Hygiene and Tropical Medicine, Keppel Street, London WCIE 7HT, UK; Jennifer.evans@lshtm.ac.uk

Accepted for publication 3 September 2004

\section{REFERENCES}

1 Evans JR, Fletcher AE, Wormald RPL, et al. Prevalence of visual impairment in people aged 75 years and older in Britain: results from the MRC trial of assessment and management of older people in the community. Br J Ophthalmol 2002;86:795-800.

2 Evans JR. Causes of blindness and partial sight in England and Wales 19901991. Studies on medical and population subjects 57. London: HMSO, 1995.

3 Owen CG, Fletcher AE, Donoghue $M$, et al. How big is the burden of visual loss caused by age related macular degeneration in the United Kingdom? Br J Ophthalmol 2003;87:312-17.

4 Evans JR, Fletcher AE, Wormald RPL. Age-related macular degeneration causing visual impairment in people aged 75 years and above in Britain. Ophthalmology 2004;111:513-17.

5 Chopdar A, Chakravarthy U, Verma D. Age related macular degeneration. BMJ 2003;326:485-8.

6 Smith W, Assink J, Klein R, et al. Risk factors for age-related macular degeneration: pooled findings from three continents. Ophthalmology $2001 ; 108: 697-704$.

7 Fletcher AE, Jones DA, Bulpitt CJ, et al. The MRC Trial of Assessment and Management of Older People in the Community: objectives, design and interventions [ISRCTN23494848]. BMC Health Services Research 2002;2:21.

8 McGraw PV, Winn B. Glasgow acuity cards: a new test for the measurement of letter acuity in children. Ophthalmol Physiol Opt 1993;13:400-4.

9 Evans JR, Fletcher AE, Wormald RPL. Causes of visual impairment in people aged 75 years and above in Britain: an add-on study to the MRC Trial of Assessment and Management of Older People in the Community. Br J Ophthalmol 2002;88:365-70.

10 Bird AC, Bressler NM, Bressler SB, et al. An international classification and grading system for age-related maculopathy and age-related macular 
degeneration. The International ARM Epidemiological Study Group. Surv Ophthalmol 1995;39:367-74.

11 De Mheen PJM, Shipley MJ, Witteman JCM, et al. Decline of the relative risk of death associated with low employment grade at older age: the impact of age related differences in smoking, blood pressure and plasma cholesterol. $J$ Epidemiol Community Health 2001;55:24-8.

12 Christen WG, Glynn RJ, Manson JE, et al. A prospective study of cigarette smoking and risk of age-related macular degeneration in men. JAMA 1996;276:1147-51.

13 Klaver CC, Assink JJ, Vingerling JR, et al. Smoking is also associated with agerelated macular degeneration in persons aged 85 years and older: the Rotterdam Study. Arch Ophthalmol 1997; 115:945.

14 Klein R, Klein BEK, Linton KLP, et al. The Beaver Dam Eye Study: the relation of age-related maculopathy to smoking. Am J Epidemiol 1993;137:190-200.

15 Klein R, Klein BE, Moss SE. Relation of smoking to the incidence of age-related maculopathy. The Beaver Dam Eye Study. Am J Epidemiol 1998; 147:103-10.

16 McCarty CA, Mukesh BN, Fu CL, et al. Risk factors for age-related maculopathy: the Visual Impairment Project. Arch Ophthalmol 2001;119:1455-62.
17 Mitchell P, Wang JJ, Smith W et al. Smoking and the 5-year incidence of age-related maculopathy: the Blue Mountains Eye Study. Arch Ophthalmol 2002;120:1357-63.

18 Seddon JM, Willett WC, Speizer FE, et al. A prospective study of cigarette smoking and age-related macular degeneration in women. JAMA 1996;276:1141-6.

19 Smith W, Mitchell P, Leeder SR. Smoking and age-related maculopathy. The Blue Mountains Eye Study. Arch Ophthalmol 1996;1 14:1518-23.

20 Vingerling JR, Hofman A, Grobbee DE, et al. Age-related macular degeneration and smoking. The Rotterdam Study. Arch Ophthalmol 1996;114:1193-6.

21 Finkel T, Holbrook NJ. Oxidants, oxidative stress and the biology of ageing Nature 2000;408:239-47.

22 Hulea SA Olinescu R, Nita S, et al Cigarette smoking causes biochemical changes in the blood that are suggestive of oxidative stress. J Environ Pathol Toxicol Oncol 1995; 14:173-80.

23 Kelly SP, Thornton J, Lyratzopolous G, et al. Smoking and blindness: strong evidence for the link but public awareness lags. BMJ 2004;328:537-8.

24 Eye Disease Case-Control Study Group. Risk factors for neovascular agerelated macular degeneration. Arch Ophthalmol 1992;110:1701-8.

\section{Get published within days of acceptance with BJO}

We are delighted to announce that the British Journal of Ophthalmology launched a "publish ahead of print" programme in March 2005. Selected papers are fast tracked and published online months before they appear in the print journal.

Papers of more significance to the international ophthalmology community are published within days of acceptance. The first published article is the raw accepted manuscript; edited and typeset versions are also published as soon as they are available.

In addition to being available on BJO Online, the publish ahead of print articles are searchable through PubMed/Medline - establishing primacy for your work. They are linked from the BJO Online home page.

The BJO's publish ahead of print programme is unique among the major ophthalmology journals - to take advantage of this service submit your papers to the British Journal of Ophthalmology using our online submission and review system Bench >Press (http://submitbjo.bmijournals.com). For further information contact the editorial office (US office choył@itsa.ucf.edu or the UK office anne.williams@bristol.ac.uk). 